\title{
The Creativity of Being Marginal: A Style of Generating Research in Education
}

\section{John D.W. Andrews}

\section{Forces That Shape Specific Research Questions}

Much of the challenge and excitement in doing intellectual work original research in education - arises for me through the juxtaposition of contrasting methods, styles or disciplines. In my experience, creativity stems from confronting incongruities and generating ways to integrate them into larger wholes. While this is a personal viewpoint, I think it finds confirmation in a considerable literature on thinking and problem-solving. This is based on the work of Piaget (Flavell, 1963), Wertheimer (1949), Hutchinson (1949), Gordon (1961), and others. What I mean to say by the title of this paper is that being "marginal," in the sociological sense of standing at the borders of several worlds, ensures me a continuous supply of incongruent experiences as grist for fruitful research ideas.

For example, it occurred to me recently that I have taken this sort of bridging stance in every intellectual and career-related role I have had. Both my undergraduate and graduate degrees were in interdisciplinary programs (spanning the social and behavioral sciences), and the three major jobs I have held have all been joint appointments, split between departments with somewhat different goals and perspec- 
tives.* Once, for a brief time, due to some confused administrative decision-making, I even held three half-time positions simultaneously on the same campus! While one might well ask why I make my life so complicated, I feel that the gains have much outweighed the difficulties. I am also sure that, if I were writing this paper from my "clinical psychologist" perspective, I could provide personal, developmental reasons why a bridging or marginal role is comfortable for me; but that is another story. In terms of present-day results, it is precisely the mixture of fertile incongruities.

What specifically are these incongruities or mixtures? Some themes are described in the following sections.

\section{The Combination of Pure and Applied}

Much of my work, both as a psychotherapist and educational development practitioner, has involved an attempt to meld these often very desperate approaches. Ideally, this should be a real synthesis, not an awkward marriage. I think that in psychology, action settings can be used to generate some of the most profound theoretical issues just because what is humanly important (and therefore worth taking action about) is also often very relevant conceptually as well. This means that when I pick immediately practical issues to research, I try to select from among the endless array of possibilities those which are connected to some broader conceptual questions; and conversely, I'm happiest when I can approach problems of implementation (intervention in consultation or psychotherapy, for example) on the basis of a consistent theory or set of research evidence. As you might imagine, I'm particularly fond of Kurt Lewin's comment that "the best way to understand something is to try to change it."

One fruitful combination of pure and applied involves adapting research instruments to serve as workshop training exercises. The research "subjects" become collaborators: they study some aspect of educational process, learn about themselves, and see that the teaching situation is one which can be studied and influenced. For example, in one project I used George Kelly's Role Construct Repertory Test (Kelly, 1955) to examine instructors' internal and external models for good teaching and the changes which occur with experience. We use 
the test in workshops by asking participants to fill out and discuss a simplified version of it in order to enhance awareness of how they conceptualize their own and others' teaching behavior. Another use of this approach stemmed from several studies I conducted with the Grasha-Reichmann Student Learning Styles Scales (Andrews, 1981a \& b; Reichmann \& Grasha, 1974), which showed how the match or mismatch between student style and teaching method affects learning. We turned this instrument into a workshop activity by asking participants to fill it out as they were when they were students. We then grouped those with similar styles together, and asked them to tell the whole group what sort of teaching their type of student would prefer.

\section{Interplay between the Personal, Experimental, and the Public "Objective," Aspects of Events}

As a consultant or psychotherapist, I often find myself emotionally involved in relationships with clients of one sort or another and acting on the basis of hunch or intuition. Yet at the same time I am committed to reaching objective conclusions, testing hypotheses, and acting on the basis of evidence rather than what may at bottom by myth or prejudice. It does no good to sacrifice either end of this polarity. To the contrary, I feel the most productive when I can crystallize my intuitive, personal reactions into something more systematic - or when those same hunches turn out to have more of an implicit framework underlying them than I had realized. My own allegiance in this dilemma is well expressed by a sign I once had in my office. Hung so that it was free to revolve, it had on one side this statement by psychological theorist George Kelly:

Man looks at his world through transparent patterns or templets which he creates and then attempts to fit over the realities of which the world is composed. The fit is not always very good. Yet without such patterns the world appears to be such an undifferentiated homogeneity that man is unable to make any sense out of it. Even a poor fit is more helpful to him than nothing at all, (Kelly, 1955)

And on the other side, this poem by e.e. cummings: 
while you and $i$ have lips and voices which are for kissing and to sing with who cares if some one-eyed son of a bitch invents an instrument to measure spring with? (Cummings, 1979)

Surely these two stances, each with its place in the scheme of things, express the need for an interplay between "right brain" and "left brain" thinking.

\section{The Clinical and the Experimental}

A familiar polarity in the realm of psychotherapy, also applicable to teaching and consultation, involves the distinction between developing a holistic formulation of a complex situation - such as a case formulation or a characterization of classroom atmosphere based on observation - and making a step-by-step or single-variable effort to identify causal relationships by means of experimental controls. People taking the clinical approach often find that their ability to make predications is less than they had estimated (Meehl, 1954), while the more rigorous method often leaves one contextless; with some wellverified propositions which become dubious when generalized to new situations or when removed from isolation and replaced in the complex welter of reality (Cronbach \& Snow, 1977).

One sphere in which I have confronted this dilemma is the use of impressions and data in assessing student response to teaching (Andrews, 1977). Informal observations are often rich and evocative, but hard to verify; and questionnaire data are clear and comprehensive, but limited in focus and somewhat sterile. We have been experimenting with how to enrich the interplay between these two. First, we do this by feeding questionnaire information back to the class which generated it, and then using the numbers as starting points for more informal and open-ended discussions of how to improve instruction. For example, one might pick out certain questionnaire items on which dissatisfaction was high, and ask students to suggest some new approaches; or select ones which showed a polarization of student reactions and hold a discussion about the differing perceptions involved. We also work in the opposite direction, by holding informal discussions with the students (usually when the instructor is absent), 
and then during the course of the meeting gradually crystallizing the group "consensus" into a series of propositions which can be checked by hand vote or by a written questionnaire tailor-made for that particular class. I find that conducting such sessions is very exciting and draws on my ability to shift rapidly from the clinical to the quantitative and vice versa.

\section{Interdisplinary Interactions}

As I mentioned above, most of my professional training has been in interdisciplinary programs, and I often look for research problems which lie at the intersection of two or more fields. Perhaps this helps explain my fascination with aptitude-treatment interaction studies. Such work intersects personality psychology, cognitive psychology, the social psychology of small groups, and educational methodology in the study of how individual characteristics influence the ability to learn in various educational settings (Cronbach \& Snow, 1977). I have a parallel interest in how teachers' personalities affect their interactions with students and constrain their freedom to adopt various specific teaching methodologies. I explored this latter issue more deeply in one paper (Andrews, 1978), co-authored with a teacher who was simultaneously a client in psychotherapy and in teaching improvement consultation.

\section{Extending Practiced Skills into Novel Settings}

This way of generating interesting incongruities involves riding a familiar horse into new landscape. Sometimes this means moving across related disciplinary boundaries, as when I discovered that skills learned in conducting family therapy gave me a foothold in functioning as an organizational development consultant. In other cases, it means using generalists skills to work at a "process level." For example, my initial forays into educational consulting worked because I had a general sensitivity to interaction processes, which could be applied to classroom dynamics, and because I knew how to design participative workshop activities appropriate for a wide variety of different specific issues. These generalist skills gave me an initial wedge into education, particularly where the subject area was alien or 
unfamiliar, and gradually I was able to turn this experience into specific hypotheses which could be tested by research.

For example, I recently completed a research project in chemistry, stimulated by the instructors' concern over student passivity. I began by observing teacher-student interactions, and by participating in them myself as a very ignorant (but non-passive) learner. From this we generated a discovery learning format, and compared it experimentally with the standard expository method (Andrews, 1981b). This was carried out in a "real life" pre-exam review session, and showed the superiority and practicality of the new method. There was also an aptitude-treatment interaction, in that self-described "independent" students had the highest quiz scores in the discovery session while "dependent" students learned better from the expository approach.

I might sum this up by saying that for me, intellectual productivity is like an arc of electricity between two poles. These poles must be just the right distance apart to produce a Zap! If they are too close together, we get current business as usual; connections are made but they don't produce much that is interesting. And if there is too much disparity, no opportunity arises for a flow to occur. This notion reminds me of the title I gave a recent article: "The Psychotherapy Neurosis: Now Bugs Eat DDT" (Andrews, 1979). The first "pole" of the title is conventional and formal in tone; the second is puzzling, evocative, metaphorical. What is the connection? This creates a buildup of intellectual "charge" which is released as the reader pursues the first few pages of the article. The two halves of the title reflect two types of thought ("left brain" and "right brain"?) and the reader gradually sees that this whimsical incongruity expresses a quite precise parallel involving the boomerang effects of two types of problemcombating methods (psychotherapy and pesticides).

\section{The Creative Process}

If the first stage of intellectual work involves setting up productive incongruities, a deliberate posing of thesis-antithesis tensions, then the second stage moves toward synthesis - a resolving of these tensions in a way that leads to new creative combinations. Seen from this standpoint, the elements sketched above become criteria for defining 
productive, applied-research questions; the resultant products should simultaneously contribute to the action and research endeavors defined by those elements. Here are some characteristics of such problems.

\section{Theoretically and Conceptually Significant}

It should shed some light on an issue of learning or communication. Thus I try to define such questions with an eye to existing theoretical formulations, and frame them in such a way that they will extend or test such assumptions.

\section{Applicable and Usable}

The adage, "There is nothing so practical as a good theory" comes to mind here. Teachers need to make basic concepts about teaching and learning a part of their own personal construct systems, and one of the best ways to do this is to provide new or improved teaching methods that are also well-rooted theoretically.

\section{Of Direct Concern to the Setting in Which I Work}

This involves the active participation of teachers and/or students, in such a way that the "research subjects"may also be "collaborators." The system under study is in effect engaging in a self-study process. Thus the researcher-subject dichotomy is overcome at least in part.

\section{Amenable to Formal Research Procedures}

Conclusions which can be documented scientifically are at once the most valid and the most credible with scholarly-minded faculty. I have found it important to blend the contextual emphasis which is essential to application with the scientific experimental-control paradigm, since the latter often has a one-variable-at-a-time emphasis which does not translate well into use by the practitioner. This blending often involves correlational analyses of naturally occurring events, content analysis of spontaneously produced materials, and aptitudetreatment interaction research.* 


\section{Dissemination and Application}

As a teaching development practitioner, I have evolved an approach to disseminating research results which blends many of the ingredients described above; the "bridging" approach helps make this communication effective. The method, which I will illustrate below, usually begins by identifying an issue which is simultaneously a campus concern and a conceptually interesting question. Such issues are ripe for a "Research and Development" effort in which new teaching approaches can be studied and then made available on campus. The problem should be defined in such a way that local faculty and TAs can identify with it and compare their own teaching with the published results. In this sense we are involved in an institutional self-study activity which taps instructors' curiosity about themselves and their colleagues. Communication of conclusions takes place via a newsletter which presents them in non-technical, implementable form, via workshops focused on the topic in question, and as an element in the consultation process.

\section{Assessing Student Understanding}

This project began with the observation that our relatively sophisticated Course and Professor Evaluation (CAPE) system generates an enormous amount of data about faculty each year, most of which is not used for teaching improvement purposes. This is partly due to uncertainty about how to apply the information, partly to indifference, and partly to the weak credibility of student evaluations in some instructors' eyes.

I decided to use this information to pinpoint a key teaching issue on campus, to test the validity of the student rating data themselves, and to create a starting-point for identifying teaching improvements. Examination of the 17-item evaluation form showed a considerable variation of item means campus-wide, and I selected a single item which was among the very lowest rated group and also seemed amenable to improvement efforts. This question asked students to rate the extent to which the professor knows if students are understanding the material, and it seemed to me that this was not only a key ingredient in effective communication of knowledge, but also an important 
aspect of good student-faculty rapport. Naturally, it is disturbing that this rating was among the lowest.

On the basis of CAPE data, we identified some variables, such as class size, which affected this rating independently of the professor's teaching. Then we located those faculty, who even in relatively large classes, had excellent ratings on this item, and arranged to interview a number of them about the techniques they used to assess student understanding. * The idea of obtaining a contrast or control group was dampened by the realistic difficulties of doing applied research: It seemed tactless to approach faculty at the low end of the scale in order to ask them what they were doing, or not doing, to elicit poor ratings!

Having obtained information about teaching techniques via openended interviewing of faculty, we cross-checked these data by visiting a number of the same teachers' classes, and asking their students to describe on a questionnaire form what the instructors did to keep in touch with students' understanding. We also conducted telephone interviews with a number of randomly selected students, asking them to describe the methods of those instructors whom they would rate highest on the same CAPE item. These three "triangulated" sources of data yielded some common themes which I combined via content analysis. Rigor in the study was enhanced by having three independent sources of information but was weakened through lack of a comparison group. Yet on balance, there seemed reason to believe that the CAPE ratings - on this time at least - did correlate with some distinctive types of teacher behavior.

On this basis we wrote up a newsletter article which stressed the sorry state of teacher-student communication as indicated by the ratings, described the research structure of the study, gave some of the background findings, and listed a variety of teaching techniques which seemed likely to enhance the professor's awareness of the students' level of understanding. I hoped this would enhance the credibility of the CAPE ratings; stimulate interest among teachers - since colleagues were the subjects of the study and since faculty could compare their own published CAPE results with the research findings; and provide some alternatives for instructors who wanted to improve their performance. 


\section{Student Participation in Discussion}

A second project (Andrews, 1980a) developed from the widespread concern expressed to me in workshops and consultation meetings, about "getting students to participate." While of course everybody wanted good quality comments about relevant points, the gut concern seemed to be with preventing those excruciating silences in which discussion dies out altogether. Once you get people saying something, you can then begin to shape discussions in the right direction. I decided that the first goal should be to study ways of getting more discussion "mileage," and I found that my intuitive sense of "discussion quality" could be boiled down to a set of simple objective indices by which to evaluate teacher questions. These consisted of counting the number of separate student responses, the number of student-to-student responses, and the number of student participants which followed each question. Bearing in mind such concepts as Guilford's (1962) distinction between convergent and divergent thinking, and Bloom's hierarchical classification of cognitive levels (Bloom, et al., 1956), I began listening for themes which distinguished questions with different "mileage" ratings. This led eventually to a content analysis coding scheme with good inter-rater reliability which confirmed some hypotheses about question structure. These results, all drawn from videotaped classes on our own campus, were written up in newsletter form with prescriptive suggestions about how to increase discussion participation. The research results also served as the basis for a workshop exercise, in which participants reproduce inductively the categories of the content analysis system.

\section{Transition from Student to Teacher}

The third endeavor began with a conceptual issue: the theme of transitions in adult development (Gould, 1978). In preparing a conference paper on the topic (Andrews, 1980b), I focused on a significant transition in the lives of the Teaching Assistants with whom I work. This is the shift from student to teacher, which is complicated by the fact that as a graduate student one does not really leave the student role behind in becoming a TA. To explore changes in attitudes and self-concept during this process, I drew on a well-developed clinical 
research instrument, George Kelly's Role Construct Repertory Test (Kelly, 1955). Using this it was possible to conduct a reasonably well-controlled study of how self- and role-perceptions develop with increasing teaching experience.

Part of the appeal this test has always had for me is its self-reflective nature. Because it is essentially a sorting and concept formation task involving one's "significant others," the test procedure itself often leads the subject to interesting new insights about himself or herself. Thus the collection of data can become a self-study procedure that helps the TA to deal with a professionally significant issue.

In this project, the combination of research findings with the self-awareness effect enable me to generate a new training activity, disseminated through newsletter and workshops for Teaching Assistants. This involved completing an abbreviated form of the research instrument, and analyzing it in terms of self-image and the conceptual "lenses" through which the individual views the teaching process. Since these concepts tend to limit how one can perceive important situations, the final stage of the activity involved "consciousness expansion": the participants borrowed each other's "lenses" and categorized their own teaching selves according to these fresh dimensions. Those who participated felt this helped them see new alternative regarding some familiar personal and professional dilemmas.

\section{In Conclusion}

Despite what is said in formal expositions of scientific method, research creativity is a very personal matter and involves intuitions, idiosyncratic needs, individual stylistic patters, and emotion-laden preconscious thinking. Studies of the creative process are full of accounts that stress such nonlinear, unsystemizable mental leaps. While it is impossible to come up with a formula for generating productive research, it is feasible - and vital - to establish the conditions under which such sparks are most likely to arise. What I have sketched in this paper is a picture of the conditions which work for me; if they are transplantable, and thereby usable by someone else, so much the better. 


\section{References}

Andrews, J.D.W. Teaching improvement viewed as team development: The class as a temporary learning organization. Paper presented at the Conference of the Network for Professional and Organizational Development in Higher Education, October 1977.

Andrews, J.D.W. Growth of a teacher. Journal of Higher Education, 1978, 49, 136-160.

Andrews, J.D.W. The psychotherapy neurosis: Now bugs eat DDT. Psycholotherapy: Theory, Research and Practice, 1979, 16, 72-78.

Andrews, J.D.W. The verbal structure of teacher questions: Its impact on class discussion. POD Quarterly, 1980, 2, 129- 163.(a)

Andrews, J.D.W. The student-teacher transition: A study of changing self-definition. Paper presented at the Conference of the Network for Professional and Organizational Development in Higher Education, October 1980.(b)

Andrews, J.D.W. Teaching format and student style: Their interactive effects on learning. Research in Higher Education, 1981, in press.(a)

Andrews, J.D.W. The effects of varying degrees of structure on the learning performance of independent and dependent students. Research in Higher Education, submitted for publication, 1981.(b)

Bloom, B.S., Englehart, M.D., Furst, E.J., Hill, W.H., \& Krathwohl, D.R. (Eds.) Taxonomy of educational objectives. New York: McKay, 1956.

Cronbach, L.J., \& Snow, R.E. Aptitudes and instructional methods. New York: Van Nostrand, 1977.

Cummings, E.E. Complete poems. New York: Liveright, 1979.

Flavell, J.H. The developmental psychology of Jean Piaget. New York: Van Nostrand, 1963.

Gordon, W.J.J. Synetics. New York: Harper, 1961.

Gould, R. Transformations. New York: Simon \& Schuster, 1978.

Guilford, J.P. Creativity: Its measurement and development. In S.J. Parnes, \& H.F. Harding (Eds.), A source book for creative thinking. New York: Scribner, 1962. Pp. 156-168.

Hutchinson, E.D. How to think creatively. New York: Abingdon- Cokesbury Press, 1949.

Jacoby, K.E. Behavioral prescriptions for faculty based student evaluations of teaching. American Journal of Pharmaceutical Education, 1976, 40, 8-13.

Kelly, G.A. The psychology of personal constructs. New York: Norton, 1955.

Meehl, P.E. Clinical versus statistical prediction: $A$ theoretical analysis and a review of the evidence. Minneapolis: University of Minnesota Press, 1954.

Reichmann, S.W., \& Grasha, A.F. A rational approach to developing and assessing the construct validity of a student learning styles scales instrument. Journal of Psychology, 1974, 87, 213-223.

Wertheimer, M. Productive thinking. New York: Harper, 1949. 
*The specific areas have included Psychology, Organizational Development, Applied Policy Sciences, Student Counseling and Psychotherapy, Information and Library Studies, and Teaching Development.

*A similar orientation to criteria of scientific validity has been suggested by Cronbach and Snow (1977) in their call for "experimental case studies" in which the effects of many simultaneously interacting variables can be assessed.

*This is similar to the procedure developed by Jacoby, Wilson, and Wood (Jacoby, 1976). 